\title{
PERCEPÇÕES DE PUÉRPERAS VÍTIMAS DE VIOLÊNCIA INSTITUCIONAL DURANTE O TRABALHO DE PARTO E PARTO \\ - revisão integrativa •
}

\author{
Bárbara Angélica Gómez Pérez*, Edilaine Varjão Oliveira**, Mariana Santos Lago*** \\ Autora correspondente: Bárbara Angélica Gómez Pérez - E-mail: bagperez@bahiana.edu.br \\ * Enfermeira Obstetra, Mestre em Enfermagem pela Universidade Federal da Bahia Professora e Orientadora do Curso de \\ Enfermagem da Escola Bahiana de Medicina e Saúde Pública \\ ** Graduanda do curso de enfermagem da Escola Bahiana de Medicina e Saúde Pública
}

\section{Resumo}

Para o presente estudo foi realizado uma pesquisa bibliográfica integrativa com abordagem qualitativa do tipo meta-estudo qualitativo. É um modelo de investigação secundária qualitativa feita através da narrativa biográfica composto por relatos de fonte primária de pesquisa qualitativa. Este estudo objetivou-se analisar os resultados de pesquisas sobre as percepções de puérperas vítimas de violência institucional no seu trabalho de parto e parto, relacionando com poder e gênero. A amostra foi composta por dez artigos indexados na base de dados LILACS, no período de 2002 a 2013 . A caracterização da violência foi embasada nas categorias de gênero e poder, na qual a partir da leitura foram surgindo várias temáticas. Constatou-se que a violência institucional está relacionada com gênero, devido à atitude dos profissionais de tentativa ou consolidação de dominação do corpo e da mente feminina, de forma persuasiva e invasiva. Os resultados desta revisão corroboram a importância de mais pesquisas sobre este tema. Dessa forma, entendemos que para que haja uma mudança neste cenário deve haver o empoderamento de conhecimentos pelas gestantes, mudanças na formação acadêmica dos profissionais e criações de políticas públicas que garantam o direito da mulher. Palavras-chave: Violência Institucional; Parto Normal; Poder; Gênero. 


\title{
PERCEPTIONS OF POSTPARTUM DURING LABOR AND DELIVERY \\ - integrative review•
}

\begin{abstract}
For the present study was conducted an integrative literature review with a qualitative approach the type qualitative meta- study. It is a model of qualitative secondary research done through biographical narrative composed of reports from primary source of qualitative research. This study aimed to analyze the results of research on the perceptions of postpartum women victims of institutional violence in their labor and delivery, relating to power and gender. The sample consisted of ten articles indexed in LILACS database in the period 2002-2013. Characterization of violence was based on the categories of gender and power, which from reading various themes were emerging. It was found that institutional gender-based violence is due to the attitude of the professionals attempt or consolidation of domination of the female body and mind, persuasive and invasive. The results of this review confirm the importance of further research on this topic. Thus, to understand that there is a change in this scenario should be to acquire knowledge by pregnant women, changes in academic and professional creations of public policies that guarantee women's right.
\end{abstract}

Keywords: Institutional Violence; Normal Birth; Power; Gender.

\section{INTRODUÇÃO}

No Brasil, o parto é considerado um evento histórico que tem apresentado grandes mudanças culturais ao longo dos anos. Essas alterações ocorreram devido ao desapropriamento do cargo de parteiras, que eram ocupados por mulheres de confiança na comunidade. As mesmas foram gradativamente sendo substituídas por profissionais que tinham o ensino superior (1). A partir disto, o cenário do parto/nascimento ficou marcado por algumas mudanças significativas, que aconteceram com o intuito de evitar o crescimento da morte materno/fetal e que desencadearam outras gravidades, como a violência institucional.(1)

Com a institucionalização do parto, a mulher passou a ser medicalizada e a sofrer intervenções cirúrgicas que muitas vezes poderiam ser evitadas. (1) O que hoje é reconhecido como uma das formas de violência obstétrica contra as mulheres, que possuem total direito de opinar e decidir sobre o que é feito com seu corpo.

A Organização Mundial de Saúde (OMS) em 2002 definiu a violência como: "O uso intencional da força física ou do poder, real ou em ameaça, contra si próprio, contra outra pessoa, ou contra um grupo ou uma comunidade, que resulte ou tenha grande possibilidade de resultar em lesão, morte, dano psicológico, deficiência de desenvolvimento ou privação".(2) Desta forma, a definição empregada pela OMS, sobre o conceito de violência está atrelada a consciência de estar praticando um ato violento de forma intencional, ocasionando danos físicos e psicológicos a outrem.

Neste contexto, "A violência institucional é aquela exercida nos/pelos próprios serviços públicos, por ação ou omissão. Podendo incluir desde a dimensão mais ampla da falta de acesso, à má quali- 
dade dos serviços. Abrangendo abusos cometidos em virtude das relações de poder e desigualdade entre usuários e profissionais dentro das instituições, até por uma noção mais restrita de dano físico intencional. Esta violência pode ser identificada de várias formas".(3)

A falta de acesso para iniciar o pré-natal; a peregrinação para encontrar uma maternidade; os espaços físicos que geralmente são hostis e não favorecem a privacidade da parturiente, são considerados alguns dos tipos de violência institucional observado dentro desse contexto. ${ }^{(4)}$

Trata-se de um tema pouco identificado e invisibilizado pelas suas vítimas, sendo em geral naturalizado e aceito por todos. Na sua forma mais especifica quando praticada dentro das maternidades durante o período de parturição é perpetrada por agentes que deveriam proteger, garantindo-lhes uma atenção humanizada, preventiva e reparadora de danos. "Uma forma, infelizmente, muito comum de violência institucional ocorre em função de práticas discriminatórias, sendo as questões de gênero, raça, etnia, orientação sexual e religião, um terreno fértil para ocorrência de tal violência".(5)

Percebe-se que a violência praticada durante o período de parturição é uma temática pouco explorada na literatura, mas se comparados com a literatura cientifica sobre a violência contra a muIher em geral, pode-se perceber que alguns autores apontam como causa da maioria das violências decorridas em maternidades, o déficit do sistema de saúde, que não oferece subsídios para que os profissionais realizem seus trabalhos, havendo então, uma grande insatisfação entre eles, neste cenário.

Sendo assim, e como reflexo disto, encontram-se profissionais desmotivados e despreparados e que muitas vezes descarregam as suas insatisfações nas usuárias, o que não justifica este comportamento.

Embora exista a Rede Cegonha, que é uma estratégia do Ministério da Saúde, que organiza uma rede de cuidados, assegurando às mulheres seus direitos como: o planejamento reprodutivo; a atenção humanizada à gravidez, (incluindo minima- mente 06 (seis) consultas de pré-natal), ao parto e ao puerpério. ${ }^{(6)}$

Apesar também do direito garantido referente à vinculação da gestante à unidade de referência e ao transporte seguro, faltam vagas nas maternidades, ${ }^{(6)}$ fazendo com que muitas mulheres sofram, tendo que peregrinar de serviço em serviço, por um atendimento. $\mathrm{O}$ que se torna até mesmo um risco, para a vida da gestante e do bebê. ${ }^{(4)}$

Diante do exposto, este estudo teve como objetivo: analisar os resultados de pesquisas, sobre as percepções de puérperas vítimas de violência institucional, no seu trabalho de parto e parto, relacionando com poder e gênero.

\section{MATERIAL E MÉTODOS}

Para o presente estudo foi realizada uma pesquisa bibliográfica integrativa, com abordagem qualitativa, do tipo meta-estudo qualitativo.

Este tipo de estudo é desenvolvido em uma sequência de etapas como: a) identificação do tema e questão de pesquisa; b) estabelecimento de critérios para inclusão e exclusão dos estudos; c) definição das informações a serem extraídas dos estudos; d) avaliação dos estudos incluídos na revisão e) interpretação dos resultados e f) apresentação da revisão/síntese do conhecimento. ${ }^{(7)}$

Ainda sobre este método, o meta-estudo qualitativo, é um modelo de investigação secundário qualitativo, feito através da narrativa biográfica, composto por relatos de fontes primárias de pesquisas qualitativas. $^{(8)}$

Em relação às etapas citadas anteriormente, segue à explanação:

a. A questão que guiou esta revisão foi a seguinte: Quais os motivos que levam uma parturiente e puérpera a sofrer a violência institucional em maternidades públicas no Brasil?

b. O levantamento bibliográfico foi intermediado através da Biblioteca Virtual de Saúde (BVS-BIREME) através da base de dados 
eletrônica Literatura Latino-Americana e do Caribe em Ciências da Saúde (Lilacs). Essa busca procedeu-se em Setembro de 2013, a partir do agrupamento dos descritores: Violência no Parto; Expectativas sobre o parto; Violência institucional mulher; Violência Institucional e poder; Episiotomia e poder; Dor no trabalho de parto.

Os critérios de inclusão para a escolha da amostra foram: artigos de pesquisa qualitativa com a temática violência institucional durante o período de parturição, que abordassem o tema violência institucional no trabalho de parto e parto, publicados no idioma português ou espanhol, com delimitação temporal de 2002 a 2013, disponíveis online, na íntegra e gratuitamente e que tenham sido publicados em periódicos. Os critérios de exclusão foram: estudos do tipo referencial teórico e revisão integrativa, assim como os que não comtemplaram os critérios de inclusão.

Os descritores foram utilizados em português, com disponibilidade do texto completo em suporte eletrônico, classificados nos estratos $A_{1}, A_{2}$ e $B_{1}$ da WebQualis, segundo orientação do Portal Capes.

A seleção dos artigos foi desenvolvida a partir da análise dos títulos, e utilização dos filtros com, o ano de publicação, idioma, assunto principal e texto completo, totalizando uma amostra de 118 artigos da área da saúde. Após a leitura dos resumos, foram selecionados 10 artigos. c. A definição das informações extraídas dos estudos foram, relatos biográficos que abordaram a experiência e percepções dos indivíduos. ${ }^{(9)}$

d. Para avaliação dos estudos incluídos na revisão integrativa, utilizou-se um guia para coleta de dados, no qual foram inseridas as informações de cada artigo.

e. Para interpretação e análise dos resultados utilizou-se o guia da coleta de dados, no qual pudemos categorizar os temas, disposto através das variáveis: objetivo, tipo de estudo, momento em que ocorre, tipo de violência, descrição da violência relacionada com poder, descrição da violência relacionada com gênero.

Foi desenvolvida análise de conteúdo temática, em três etapas: Pré-análise, exploração do material e interpretação dos resultados. ${ }^{(10)}$

f. A partir da amostra, os resultados da revisão integrativa, serão apresentados por meio de tabelas, gráficos e relato biográfico.

\section{RESULTADO E DISCUSSÃO}

Esta pesquisa foi constituída por artigos publicados no Brasil. A amostra foi composta de dez artigos científicos. Em seguida foram consultadas as fontes de pesquisa, na qual foram selecionados relatos que cumpriram os critérios de inclusão.

Quadro 1 - Artigos que compuseram o corpo de análise da categoria: percepções de puérperas durante o trabalho de parto e parto: revisão integrativa Brasil, 2002-2013

\begin{tabular}{|c|c|c|c|}
\hline ID & REFERÊNCIAS DOS ARTIGOS QUE COMPUSERAM O CORPUS DE ANÁLISE TEMÁTICA & $\begin{array}{l}\text { WEB } \\
\text { QUALIS }\end{array}$ & ANO \\
\hline 15 & $\begin{array}{l}\text { Hotimsky SN et al. O parto como eu vejo... ou como eu o desejo? Expectativas } \\
\text { de gestantes, usuárias do SUS, acerca do parto e da assistência obstétrica. Cad. } \\
\text { Saúde Pública, Rio de Janeiro, v. 18, n. 5, p.1303-1311, set. } 2002 \text {. }\end{array}$ & A2 & 2002 \\
\hline 27 & $\begin{array}{l}\text { Lopes RCS et al. O antes e o depois: expectativas e experiências de mães sobre } \\
\text { o parto. Reflexão e Crítica, Rio Grande do Sul, p.247-254; } 2005 .\end{array}$ & $\mathrm{Bl}$ & 2005 \\
\hline
\end{tabular}


Quadro 1 - Artigos que compuseram o corpo de análise da categoria: percepções de puérperas durante o trabalho de parto e parto: revisão integrativa Brasil, 2002-2013

\begin{tabular}{|c|c|c|c|}
\hline ID & REFERÊNCIAS DOS ARTIGOS QUE COMPUSERAM O CORPUS DE ANÁLISE TEMÁTICA & $\begin{array}{c}\text { WEB } \\
\text { QUALIS }\end{array}$ & ANO \\
\hline 31 & $\begin{array}{l}\text { Dias MAB, Deslandes SF. Expectativas sobre a assistência ao parto de mulheres } \\
\text { usuárias de uma maternidade pública do Rio de Janeiro, Brasil: os desafios de } \\
\text { uma política pública de humanização da assistência. Cad. Saúde Pública, Rio de } \\
\text { Janeiro, p.2647-2655, dez; } 2006 \text {. }\end{array}$ & A2 & 2006 \\
\hline 39 & $\begin{array}{l}\text { Griboski RA, Guilhem D. Mulheres e profissionais de saúde: o imaginário cultural } \\
\text { na humanização ao parto e nascimento. Texto Contexto - Enferm, Florianópolis, } \\
\text { v. 15, n. 1, p.107-114; } 2006 \text {. }\end{array}$ & A2 & 2006 \\
\hline 16 & $\begin{array}{l}\text { Wolff LR, Waldow VR. Violência Consentida: mulheres em trabalho de parto e } \\
\text { parto. Saúde e Sociedade, São Paulo, v. 17, n. 3, p.138-151; } 2008 .\end{array}$ & $\mathrm{Bl}$ & 2008 \\
\hline 32 & $\begin{array}{l}\text { Santos JO, Shimo AKK. Prática rotineira da episiotomia refletindo a desigualdade } \\
\text { de poder entre profissionais de saúde e mulheres. Esc Anna Nery Rev Enferm, São } \\
\text { Paulo, p.646-650, dez; } 2008 \text {. }\end{array}$ & $\mathrm{Bl}$ & 2008 \\
\hline 29 & $\begin{array}{l}\text { Davim RMB, Torres GV, Dantas JC. Representação de parturientes acerca da dor } \\
\text { de parto. Rev. Eletr. Enf, Rio Grande do Norte, p.100-109, Ol out; } 2008 .\end{array}$ & $X$ & 2008 \\
\hline 33 & $\begin{array}{l}\text { Aguiar JM. Violência institucional em maternidades públicas: hostilidade ao invés } \\
\text { de acolhimento como uma questão de gênero [tese]. São Paulo: Faculdade de } \\
\text { Medicina da Universidade de São Paulo, São Paulo, } 2010 \text {. }\end{array}$ & $\mathrm{Bl}$ & 2010 \\
\hline 17 & $\begin{array}{l}\text { Aguiar, JM \& D'oliveira, AFP Violência institucional em maternidades públicas } \\
\text { sob a ótica das usuárias. Interface- Comunic, Saúde, Educ 15(36): 79-91; } 2011 .\end{array}$ & $\mathrm{Bl}$ & 2011 \\
\hline 28 & $\begin{array}{l}\text { PINHEIRO, Bruna Cardoso; BITTAR, Cléria Maria Lôbo. Expectativas, percepções } \\
\text { e experiências sobre o parto normal: relato de um grupo de mulheres. Revista de } \\
\text { Psicologia, São Paulo, v. } 25, \text { n. 3, p.586-602, } 2013 \text {. }\end{array}$ & $\mathrm{Bl}$ & 2013 \\
\hline
\end{tabular}

O gráfico a seguir indica que houve um aumento de publicações durante o período de 2006 a 2013. Desta forma, este acontecimento pode estar relacionado com a consolidação de movimentos hu- manísticos ocorridos no Brasil, após a "Conferência Internacional sobre Nascimentos e Partos" (11) e com a criação da "Lei do acompanhante" $n^{\circ} 11.108$, 07 de abril de 2005. ${ }^{(12)}$ (Gráfico 1)

Gráfico 1 - Distribuição de artigos segundo ano de publicação. Brasil, 2002 - 2013

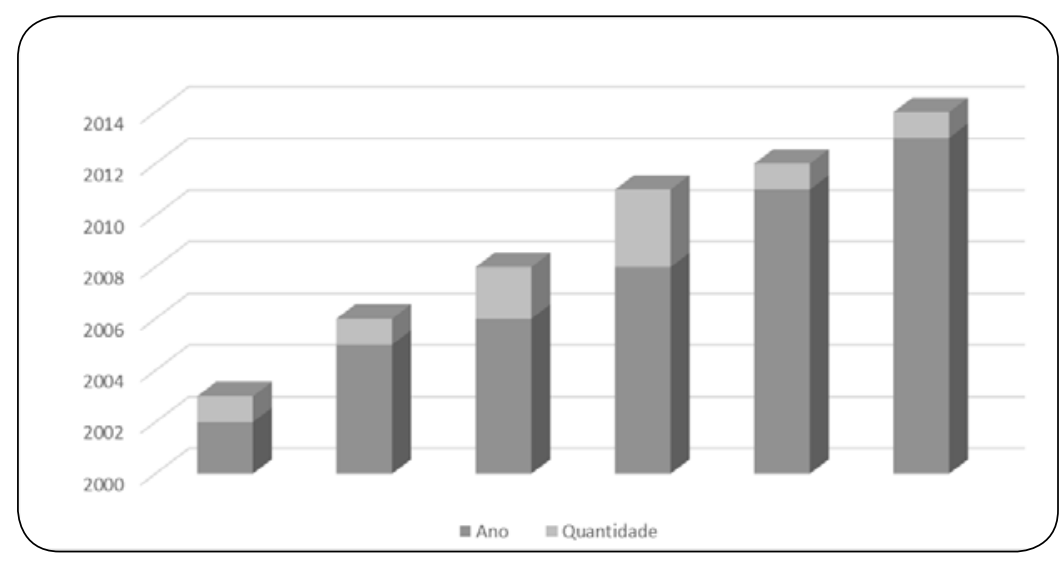


A seguir, estão as duas categorias de análise encontradas. Após a análise integrativa qualitativa dos resultados nos trabalhos selecionados, seguindo o método de análise já definido.

\section{VIOLÊNCIA INSTITUCIONAL E GÊNERO}

O conceito de violência de gênero deve ser visto como um elemento que é embasado nas relações humanas entre os sexos feminino e masculino, no qual nesta relação há o empoderamento da classe dominante de forma genuína e inquestionável. ${ }^{(13)}$

Gênero é diferente de sexo, ou seja, enquanto sexo está relacionado com a identidade biológica, gênero está ligado aos papéis desempenhados por homens e mulheres. Faz parte de uma construção social como sujeito masculino e feminino.

O gênero representa uma diferenciação, podendo até mesmo ser positivo. Contudo, é extremamente negativo quando as diferenças entre homens e mulheres tornam-se hierárquicas, seja para inferiorizar a mulher, como ocorre em todas as sociedades em maior ou menor grau, seja na direção contrária. ${ }^{(14)}$

De acordo com os relatos abaixo, percebe-se o controle do patriarcado sobre o corpo da muIher, no momento em que as obrigam a serem submissas.

Ah, (...) minha mãe fala que a gente começa gritar, o médico briga com a gente, deixa a gente mais tempo lá na mesa. ${ }^{(15)}$

[...] aquilo ali é a rotina deles [...], a gente tem que aceitar todos os tratamentos, não pode reclamar de nada [...]. ${ }^{(16)}$

Até a enfermeira lá falou assim, a estagiária falou: 'Olha, isso mesmo. Continua assim [quieta] porque geralmente eles judiam um pouco quando a mulher dá trabalho. ${ }^{(17)}$
As relações de poder são assimétricas, ou seja, os homens desempenham papéis sociais dominantes em relação às mulheres, que devem ser dóceis e obedientes. ${ }^{(18)}$

Isto ocorre porque "a força particular da sociodicéia masculina lhe vem do fato dela acumular e condensar duas operações: ela legitima uma relação de dominação inscrevendo-a em uma natureza biológica que é por sua vez ela própria uma construção social naturalizada".(19)

A violência estrutural é aquela existente nas mais diversas esferas da sociedade e nas estruturas que a compõem como, a família, os sistemas culturais, econômicos e políticos. E essa violência oprime certos grupos. ${ }^{(20)}$

A violência de gênero, um tipo de violência estrutural, está enraizada, já que está presente, em maior ou menor grau, nos diversos espaços da sociedade. E lamentavelmente, este abuso é levado para dentro do sistema de saúde.

Dessa forma, percebe-se que as mulheres são vítimas tanto da violência institucional em sua forma mais ampla, devido ao sistema que não funciona de forma correta, quanto da violência cometida por profissionais, quando deixam seus valores socioculturais influenciarem no cuidado prestado.

O desenvolvimento da prática médica em realizar partos iniciou-se por homens, estes, por sua vez, estavam em uma posição privilegiada na sociedade, assim eles terminaram por perpetrar a dominação e, consequentemente, a violência no trabalho de parto e parto. ${ }^{(21)}$

As mulheres que entraram posteriormente na medicina tiveram homens como professores, à medicina era uma profissão masculina, logo as estudantes aprenderam com homens, a forma considerada correta de tratar as parturientes, ou seja, como um objeto. ${ }^{(22)}$

O exemplo explícito disto tem-se a mais célebre das parteiras brasileiras, Madame Durocher, primeira mulher a ser recebida como membro titular na Academia Imperial de Medicina, que se vestia como homem para ser aceita, pois exercia uma profissão masculina. ${ }^{(23)}$ 
Percebe-se que houve uma reprodução deste comportamento ao longo dos anos.

Isto ocorre porque as mulheres estão inseridas em uma sociedade historicamente patriarcal, gerando dessa forma, uma violência de comportamento como centro do paradigma cartesiano que fundou as bases da dominação masculina no ocidente [...] Essa dominação masculina está presente no inconsciente coletivo, que não a percebe mais como uma forma de dominação. ${ }^{(19)}$

Nos relatos abaixo fica claro como a medicina obstétrica usa o corpo da mulher como objeto de estudo, desapropriando-a como sujeito de ação.

[...] A gente fica ali muito exposta, porque eram muitos estudantes, muita gente, ficam 10 [pessoas], mais ou menos, não sei quantos $[\ldots]^{(16)}$

[...] o toque [vaginal] era feito por mais pessoas, tinha uma médica que estava fazendo, depois trocou o plantão, aí veio mais gente, acho que uns dez estavam lá [...] uns cinco mais ou menos fizeram o toque na mesma hora [...] fizeram, e depois passava um tempo, e aí vinham tudo ao redor de novo [...] incomoda um pouco, incomodou porque machuca a gente [...]. ${ }^{(16)}$

A institucionalização do parto surgiu também, não somente para reduzir os índices de mortalidade materna, mas para estudar a gestação e o parto, dessa forma emergiu a obstetrícia, uma nova área médica.

O modelo tecnocrático trata da "mecanização do corpo humano, bem como definir o corpo-máquina como o próprio objeto".(24)

Neste modelo, o corpo masculino foi visto tendo um bom funcionamento, já o corpo feminino foi olhado com suspeitas, cheio de defeitos, precisando ser "consertado". O parto surge como momento de uma máquina caótica e não confiável. ${ }^{(24)}$

Por exemplo, o ensino da obstetrícia traz em seus livros, o estudo do processo de nascimento relacionando com uma máquina, quando diz: “mo- tor, objeto e trajeto", referindo o motor às contrações, o objeto ao feto e o trajeto a pelve materna. ${ }^{(25)}$

Assim, de forma metafórica, pode-se dizer que o "hospital se tornou uma fábrica, o corpo da mãe uma máquina e o bebê o resultado de um processo de produção industrial". ${ }^{(24)}$

O modelo tecnocrático está presente na obstetrícia e termina por ser uma forma de violência, pois não fornece o apoio que as parturientes necessitam.

[...] A violência é a ação que trata um ser humano não como sujeito, mas como uma coisa. Esta se evidencia pela passividade, pela inércia e pelo silêncio, de modo que, quando a atividade e a fala do outro são impedidas ou anuladas, há violência. ${ }^{(26)}$

Sabe-se que o contato e o carinho, são fatores poderosos que podem influenciar de forma positiva a experiência do parto.

Nestes relatos observa-se que a temática dor é encarada como algo ruim, devido às representações sociais, culturais e psicológicas construídas ao longo dos anos. A dor do parto é entendida como uma questão de gênero, pois é vista como um preço a ser pago pela sexualidade e maternidade.

É que, em relação, assim, eu tenho medo que dói, então o meu medo maior é que vai doer bem mais pra sair o bebê, até eu tenho médico sexta-feira e vou conversar sobre isso com ele, que o meu medo maior acho que é esse. ${ }^{(27)}$

Ah, eu preferia cesárea. Porque eu não senti nada do primeiro, aí eu tenho medo, sei lá, eu tenho medo de não dá conta... ${ }^{(28)}$

... é uma dor muito forte, é horrorosa, horrivel...(29)

[...] ela tava pra ganhar neném, né? E ela tava chorando [...] a mulher chegou pra ela, falou assim: "Ah, cê tá chorando por quê?", Ela: "Ai, porque tá doendo, eu acho que vou ganhar", Falou assim: "Mas na hora de fazer você chorou?". (15) 
A violência estrutural está perpetrada nas mais diversas classes sociais e espaços da sociedade. Ela estabelece dentre diversas coisas, o limite culturalmente aceito de percepção de vários fenômenos, como por exemplo, a ocorrência de dor.

O parto encontra-se imerso neste campo cultural mais amplo, como sendo um acontecimento que transfixa todas as sociedades e espaços. O mesmo está tão presente no imaginário das pessoas que quando se fala em parto, a primeira ideia que vem a mente está relacionada com a dor, como se não houvesse parto sem sofrimento. ${ }^{(18)}$

Como exemplifica o relato "Mas na hora de fazer você chorou?". Esta frase vinda de um profissional, nos mostra que a relação sexual é vista como algo sujo e que por essa razão, a mulher deve sofrer as dores do parto como forma de punição pelo ato cometido.

Os relatos seguintes mostram que além da sexualidade, a maternidade também tem relação com as dores do parto, e é vista como forma de punição, pois o filho é um prêmio. Muitas mulheres tem a percepção de que, para ser uma boa mãe é necessário sofrer as dores do parto, para que dessa forma possa cumprir seu papel. ${ }^{(29)}$

[...] a dor é horrivel, mas é a melhor coisa, é a realização do sonho de qualquer mulher ter um filho com dor, cesárea eu não recomendo... ${ }^{29)}$

[...] a dor não é muito boa não, mas eu me sinto bem porque está vindo a minha filha, a gente resiste por causa da filha, quando ela nascer é mais emocionante... ${ }^{(29)}$

Este pensamento contribui para naturalização da violência, já que as mulheres acham normal sentir dor, sofrer durante o parto.

Desde o Livro Bíblico do Gênesis, quando Eva conheceu o pecado e desvirtuou o resto da humanidade ouviu de Deus: "e tu mulher, parirás com dor os seus filhos". ${ }^{(30)}$

Pode-se perceber que essa associação de parto com dor presente no imaginário da população, advém do pensamento bíblico de que as mulheres devem sofrer, afinal para eles, "Eva" comeu o fruto proibido. ${ }^{(18)}$

Entretanto, esse pensamento não permanece somente na bíblia, ele serve de justificativa para que muitos profissionais de saúde cometam a violência institucional. Eles poderiam tomar atitudes que minimizassem a dor do parto como, por exemplo, a escolha da posição mais confortável ou o acolhimento, mas não o fazem porque as mulheres devem sentir dor, ou porque sentir muita dor no parto é considerado normal.

Sendo assim, a banalização a todas as formas de violência vivenciadas pelas mulheres durante o período de parturição faz com que estas se tornem reféns do medo de morrer ou de perder o bebê, são coagidas e permanecem em silêncio.

\section{VIOLÊNCIA INSTITUCIONAL E PODER}

A violência praticada em mulheres no período gestacional tem início muito antes da parturição. Começa desde o pré-natal, realizado muitas vezes tardiamente, até por fim na sofrida peregrinação para encontrar a maternidade em que será realizado o parto. Desta forma, essas mulheres, apresentam seus direitos negligenciados pelos serviços de saúde, que não funcionam corretamente. Como mostra o relato abaixo:

Ah! Foi horrivel! [...] primeiro eu cheguei num hospital onde eu não tive vaga porque aparelhos estavam quebrados é [...] eu tinha quinze anos, [...] fui transferida de ambulância. Até aí foi ótimo. [...] eles não me deixaram com acompanhante, sendo que eu tinha direito [...] eu fui internada sete e pouca e só fui ter meu filho cinco horas da tarde. E demorou muito. Deixam as pessoas jogadas. O médico era muito ignorante. ${ }^{(31)}$

Segundo Chauí, a violência é a "conversão de uma diferença e de uma assimetria numa relação 
hierárquica de desigualdade com fins de dominação, de exploração e de opressão. Isto é, a conversão dos diferentes em desiguais e a desigualdade em relação entre superior e inferior [...]".(26)

$A$ violência vem muitas vezes disfarçada em forma de poder. A mesma nem sempre aparece em forma física e sim, em disposição intelectual, onde o profissional usa seu conhecimento científico, como forma coerente de manipulação.

Os fatores mais relatados pelas puérperas em pesquisas aparecem imersos no campo das relações distantes entre médico x paciente, a autoridade médica, a falta de informações fidedignas e principalmente das tomadas de decisões verticalizadas, onde o médico continuamente é o detentor do maior nível de conhecimento e do "corpo" desta mulher. Sem considerar o saber empírico e autonomia da mesma. Assim, descrevem os relatos abaixo:

Ninguém me orientou nada. Eu acho que faltô informação. Eu recebi uma anestesia, por causa que a pressão tava subindo [...]. Então eles antecipô. Desde que rompeu a bolsa, né, eles deram uma anestesia, puseram o soro, não esperaro nem uns quinze minuto, nada disso, e isso já foi pro centro cirúrgico, né, pro centro obstétrico e já fizero uma anestesia e começô. Ele tipo induziu o parto, né, adiantô o parto. ${ }^{(28)}$

Nunca ouvi falar disso. Eu nem sabia que fazia pique [...] Nunca ouvi falar de pique na minha vida, nunca, nunca, nunca. ${ }^{(32)}$

Chegando lá, eu tive que fazer a limpeza, eles limparam tudo direitinho. ${ }^{(33)}$

Ai, que a gente precisa tê calma. Normal, que você tem que fazê bastante força, ficá na posição certa, se for cesárea, você tem que ficá mais calma, porque é uma injeção que toma. (28)
As práticas que são frequentemente usadas de modo inadequado são claramente prejudiciais ou ineficazes, como: o uso rotineiro de enema; uso liberal e rotineiro de episiotomia; exames vaginais repetidos ou frequentes; tricotomia sem autorização; restrição hídrica e alimentar; uso rotineiro de posição supina durante o trabalho de parto e exame retal, no qual devem ser eliminadas. (34)

Deste modo, as mesmas sofrem com vários tipos de violência verbal e física durante o processo de parturição, incluindo: a negação no alívio da dor quando tecnicamente indicado; impedimento da posição que lhes deixem mais confortáveis; tratamento áspero e grosseiro, humilhação; xingamentos; proibição de gritar e ter um acompanhante, tanto no trabalho de parto e parto. ${ }^{(35)}$

Os profissionais de saúde, médicos, enfermeiros e técnicos de enfermagem, entre outros, os que de alguma forma participam do trabalho de parto/ parto, trazem discursos que funcionam como verdadeiros para as parturientes, mas que na realidade não são, além de serem muitas vezes violentos.

Infelizmente, dentro da realidade do nosso país, não são somente as puérperas que sofrem com a desumanização e falta de informação dos profissionais. Então, a portaria $n^{\circ} 371$ de 07 de maio de 2014, atualiza diretrizes de atenção integral e humanizada ao RN no SUS e aborda que o profissional tem de permitir o contato inicial pele a pele da mãe com o bebê. ${ }^{\left({ }^{6}\right)}$ Portanto abster-se disto, significa estar cometendo também uma violência contra a mãe e principalmente contra a criança. Como exemplo dos discursos irreais, de alguns profissionais, seguem o relato a seguinte:

[...] Eu cheguei segunda-feira de noite, era um plantão, a médica residente passou para o médico que estava comigo e o médico disse que era para fazer cesárea. Embora eu não quisesse, mas ele estava falando que era melhor para mim, eu tive que aceitar é claro, não vou discutir com um profissional que sabe mais do que eu. ${ }^{(16)}$ 
Percebe-se que as parturientes aceitam estes discursos, pois creem que os profissionais de saúde detêm um maior conhecimento técnico-científico e consequentemente, isto lhe concedem poderes específicos.

Segundo Foucault, "Vivemos em uma sociedade que em grande parte marcha ao compasso da verdade, ou seja, que produz e faz circular discursos que funcionam como verdade, que passam por tal e que detêm por este motivo poderes". ${ }^{(37)}$

O discurso dos profissionais de saúde, muitas vezes é usado como forma de persuasão sobre os pacientes, para atender um desejo próprio de algo que está enraizado ou culturalmente disseminado na profissão e que muitas vezes não é verdadeiro. Ratificam isto, a partir dos trechos abaixo:

[...] e pelo fato, assim, da minha outra médica, do meu primeiro filho tê falado que a minha estrutura óssea, mesmo que eu dilatasse, o tanto suficiente, o nenê não ia tê passagem pra nascê, por causa do meu quadril sê muito estreito. ${ }^{(28)}$

Ai, muitas coisa elas fala, porque cada um explica dum jeito, né. Aí, a gente tem que ir pelo que acha melhor pra gente, né. ${ }^{(28)}$

Segundo Foucault, "O poder é um feixe de relações mais ou menos organizado, mais ou menos piramidalizado, mais ou menos coordenado". (37)

Em se tratando de partos nos hospitais públicos, essas relações de poder (micro-poderes), terminam por se dar de cima para baixo, sendo que os profissionais de saúde estão em cima da pirâmide e as parturientes embaixo, em uma relação assimétrica e, muitas vezes, até violenta. Segundo confirma o relato abaixo:

Aí a médica abriu; apertou aqui; aí viu que não era normal; aí ela: 'mãezinha, calma. Você tem que confiar em mim. Se você não confiar em mim você vai confiar mais em quem?'. Eu falei: 'ó, eu quero que você faça alguma coisa porque esse sangue todo não é normal!'. Já estava vindo aqui em cima de mim ó. Aquele sangue vivinho. Era tanto sangue que se eu não falasse nada eu acho que eu ia morrer lá. Aí como ela viu que não estava normal, me deram lá o remédio, aí parou. ${ }^{(17)}$

O poder nunca será prioridade de um indivíduo, pois se um grupo se mantiver unido, em comum acordo haverá poder. ${ }^{(38)}$

Para isto, não basta culpar somente as puérperas de desunião e sim todo o sistema público e de profissionais, que deveriam em uníssono, rever seus papéis dentro da sociedade, classe e principalmente como pessoas humanas. Assim desenvolvendo a construção de um modelo igualitário e digno para o fruto da vida, que é o nascimento.

A baixa escolaridade, atrelada à falta de informação, favorecem as desigualdades tornando as relações de poder no trabalho de parto e parto autoritário e humilhante. A prevenção da violência real ou simbólica contra a mulher passa pelas ações de empoderamento das mesmas. ${ }^{(39)}$ Como exemplo disto, segue os discursos abaixo:

[...] não vou discutir com um profissional que sabe mais do que eu; [...] não perguntavam a minha opinião [...]. ${ }^{(16)}$

Os direitos eu não sei explicar, eu sei que tenho que ser atendida, da melhor forma possivel, melhor condição, mas todos os direitos, não sei [... ${ }^{(40)}$

As mulheres devem ser respeitadas em suas decisões. Para isto, as mesmas devem possuir o saber e manterem-se unidas, para que desta forma essas relações de poder tornem-se horizontais, comprometendo assim o ápice da pirâmide hierárquica e colocando o fim nas relações tão desiguais e verticalizadas. 


\section{CONCLUSÃO}

Dentro da realidade vista diante dos relatos das puérperas concluímos que, a violência contra a mulher, dentro de uma perspectiva de gênero e poder profissional, tem se tornado uma prática cada dia mais comum nos serviços de saúde.

Percebe-se que, esta banalização dos profissionais, também está atrelada a uma raiz cultural e inclusive religiosa, de que a mulher deve sofrer. Isto é, a naturalização da dor, devido à mesma ter tido prazer sexual e novamente relacionado a uma ação de violência designada pelo gênero. Desta forma, percebe-se que deve haver uma mudança na criação dos filhos, para que possamos descontruir valores e paradigmas que foram construídos durante anos.

Sabe-se que a falta de discernimento do que é correto ou errado, faz com que alguns profissionais usem do seu poder, para de forma persuasiva induzir as pacientes. Para isto utiliza-se de mentiras, que constantemente funcionam como verdades. Isto vem cada vez mais, Ihe acarretando poder e flexibilidade para conduzir o parto da maneira que the for mais conveniente. $\mathrm{O}$ que vem sido caracterizado como abuso do poder.

As parturientes que sofrem violência institucional no trabalho de parto e parto são, muitas vezes, acusadas de consentirem a violência, de serem coparticipes. Porém, as mulheres que são portadoras de uma consciência de dominadas, não denunciam ou não reclamam porque tem medo, ou mesmo por não terem conhecimento sobre os seus direitos. Elas desistem, frente às ameaças ou violências concretas. Logo, deve-se investir em ações que estimulem e promovam a autonomia das mulheres, retire-as da posição de inferiores, inclusive dentro do próprio ambiente hospitalar.

Os profissionais devem desconstruir a ideia de que a mulher deve ser submissa, seja por questões relacionadas a gênero ou a poder. Então, deve-se incentivar a adesão cada vez mais dos profissionais, para a construção da educação continuada, de forma construtiva e horizontal, podendo haver uma troca de saberes, empíricos e técnicos, de onde só apresentem somas e nenhuma perda.

Portanto, acredita-se que para melhorar a assistência prestada à parturiente, deve-se começar primeiramente pela transformação na sociedade, desconstruindo o papel de mulher submissa, convencendo-as a iniciar este modelo, desde a criação dos seus filhos. Além disto, deve haver o empoderamento de conhecimento pelas gestantes, mudanças na formação acadêmica dos profissionais, de forma que, essas mudanças ocorram de dentro para fora e consequentemente, criações de políticas públicas que garantam o direito das mulheres e das crianças, como ratifica a nova portaria de $n^{\circ}$ 371 de 07 de maio de 2014.

\section{REFERÊNCIAS}

1. Mott ML. Parto. Revista Estudos Feministas. 2002 [acesso em 10 mar 2O14]; 1O(2): 399-401. Disponível em: http://www.redalyc.org/articulo. oa?id=38110209

2. Organização Mundial de Saúde. Relatório mundial sobre violência e saúde. Brasília: OMS/ Opas; 2002.

3. Brasil. Ministério da Saúde. Secretaria de Políticas da Saúde. Violência intrafamiliar: orientações para a prática em serviço. Brasília: Ministério da Saúde; 20O2. Caderno de Atenção Básica, n 8. Série A Normas e Manuais técnicos, 131.

4. Menezes DCS, Leite IC, Schramm JMA, Leal MC. Avaliação da peregrinação anteparto numa amostra de puérperas no Município do Rio de Janeiro, Brasil, 1999/2001. Cad. Saúde Pública. 2006 [acesso em 10 mar 2014]; 22(3): 553-559. Disponível em: http://www.scielo. $\mathrm{br} / \mathrm{sciel}$.php?script=sci_arttext\&pid=SO1O2311X2006000300010\&lng=en.

5. Taquette SR. Violência contra a mulher adolescente/jovem. Rio de Janeiro: EDUERJ; 2007.

6. Brasil. Ministério da Saúde. Portaria n 1.459, de 24 de junho de 2011. Institui no âmbito 
do Sistema Único de Saúde - SUS - A Rede Cegonha. Brasília; 2011.

7. Mendes KDS, Silveira RCCP, Galvão CM. Revisão integrativa: método de pesquisa para a incorporação de evidências na saúde e na enfermagem. Texto \& contexto enferm. 2008 [acesso em 10 mar 2014]; 17(4):758764. Disponível em: http://www.scielo.br/ scielo.php?script=sci_arttext\&pid=SO1O407072008000400018\&lng=en.

8. Hueso MC. Metaestudio cualitativo a través del relato biográfico. Un modelo de investigación secundaria cualitativa. Arch Memoria. 2008. [acesso 12 mar 2014]; 5(3). Disponível em: http:// www.index-f.com/memoria/5/e30801.php.

9. Amezcua M, West CM. Cómo elaborar un relato biográfico. Arch Memoria. 2004. [acesso 12 mar 2014]; (1). Disponível em: http://www.index-f. $\mathrm{com} / \mathrm{memoria} / \mathrm{metodologia.php.}$

10. Bardin L. Análise de contéudo. 70. ed. Lisboa: Lda; 1977.

11. Tornquist CS. Parto e poder o movimento pela humanização do parto no Brasil (tese). Santa Catarina: Universidade Federal de Santa Catarina; 2004.

12. Brasil. Lei n ${ }^{\circ} 11.108$, de 7 de abril de 2005. Garantir as parturientes o direito à presença de acompanhante durante o trabalho de parto, parto e pós-parto imediato, no âmbito do Sistema Único de Saúde - SUS. 2005 [acesso em 12 mar. 2014]. Disponível em: http:// www.planalto.gov.br/ccivil_O3/_Ato2OO42006/2005/Lei/L11108.htm.

13. Scott J. Gênero: uma categoria útil de análise histórica. In: Mulher e realidade: mulher e educação; 1990.

14. Saffioti HIB. Violência de gênero no Brasil atual. Revista Estudos Feministas. 1994.

15. Hotimsky SN, Rattner D, Venancio SI, Bógus CM, Miranda MM. O parto como eu vejo... ou como eu o desejo?: expectativas de gestantes, usuárias do SUS, acerca do parto e da assistência obstétrica. Cad. Saúde Pública. 2002 [acesso em 17 mar. 2014]; 18(5):13031311. Disponível em: http://www.scielo.br/ scielo.php?script=sci_arttext\&pid=SO1O2$311 \times 2002000500023 \& \operatorname{lng}=e n$. http://dx.doi. org/10.159O/sO1O2-311X2002000500023.
16. Wolff LR, Waldow VR. Violência consentida: mulheres em trabalho de parto e parto. Saúde Soc. 2008;17(3):138-151.

17. Aguiar JM, D'oliveira AFP. Violência institucional em maternidades públicas sob a ótica das usuárias. Interface (Botucatu). 2011 [acesso em 03 abr. 2014]; 15(36): 7992. Disponível em: http://www.scielo.br/ scielo.php?script=sci_arttext\&pid=S141432832011000100007\&lng=en.

18. Teixeira NZF, Pereira WR. Parto hospitalar: experiências de mulheres da periferia de Cuibá-MT. Rev. bras. enferm. 2006 [acesso em $\mathrm{O} 3 \mathrm{abr}$. 2014]; 59(6): 740744. Disponível em: http://www.scielo.br/ scielo.php?script=sci_arttext\&pid=SOO34$71672006000600004 \&$ lng $=$ en.

19. Bourdieu P. A dominação masculina. Trad. de Maria Helena Kuhner. $2^{\mathrm{a}}$ ed. Rio de Janeiro: Bertrand Brasil; 2002.

20. Minayo MCS. A violência social sob a perspectiva da saúde pública. Cad. Saúde Pública. 1994.

21. Brenes $A C$. História da parturição no Brasil no século XIX. Cad. de Saúde Pública. 1991.

22. Nozawa MR, Schor N. O discurso de parto de mulheres vivenciando experiências da primeira gestação. Saúde e Soc. 1996 [acesso em 14 abr. 2014]; 5(2): 89119. Disponível em: http://www.scielo.br/ scielo.php?script=sci_arttext\&pid=SO1O412901996000200007\&lng=en.

23. Souza FJA. O ensino da clinica obstétrica na Universidade da Bahia. Salvador: Universidade Federal da Bahia; 1967.

24. Davis-Floyd R. The Technocratic, Humanistic, and Holistic Paradigms of Childbirth. Int. j. gynecol. obstet. 2011 [acesso em 20 abr. 2014]. Disponível em: http://davis-floyd.com/thetechnocratic-humanistic-and-holistic-paradigmsof-childbirth/

25. Rezende J. Obstetrícia. $6^{\mathrm{a}}$ ed. Rio de Janeiro: Guanabara Koogan; 1992.

26. Chauí M. Participando do debate sobre mulher e violência. $4^{\mathrm{a}}$ ed. Rio de Janeiro: Zahar; 1985.

27. Lopes RCS, Donelli TS, Lima CM, Piccinini CA. $O$ antes e o depois: expectativas e 
experiências de mães sobre o parto. Psicol. reflex. crít. 2005 [acesso em 14 abr. 2014]; 18(2): 247-254. Disponível em: http://www.scielo. $\mathrm{br} / \mathrm{scielo}$.php?script=sci_arttext\&pid=SO1O279722005000200013\&lng=en\&tlng=pt.

28. Pinheiro BC, Bittar CML. Expectativas, percepções e experiências sobre o parto normal: relato de um grupo de mulheres. Rev. Psicol. 2013.

29. Davim RMB, Torres GV, Dantas JC. Representação de parturientes acerca da dor de parto. Rev. eletrônica enferm. 2008 [acesso em 25 abr. 2014]; 1O(1). Disponível em: http:// www.revistas.ufg.br/index.php/fen/article/ view/7685/5459.

30. Bíblia. Português. Bíblia Sagrada. Trad. de Centro Bíblico Católico. 34ª ed. rev. São Paulo: Ave Maria; 1982.

31. Dias MAB, Deslandes SF. Expectativas sobre a assistência ao parto de mulheres usuárias de uma maternidade pública do Rio de Janeiro, Brasil: os desafios de uma política pública de humanização da assistência. Cad. Saúde Pública. 2006 [acesso em 20 abr. 2O14]; 22(12): 2647-2655. Disponível em: http://www.scielo. $\mathrm{br} / \mathrm{scielo}$.php?script=sci_arttext\&pid=SO1O2$311 \times 2006001200014 \&$ lng=pt.

32. Santos JO. Shimo AKK. Prática rotineira da episiotomia refletindo a desigualdade de poder entre profissionais de saúde e mulheres. Esc. Anna Nery Rev. Enferm. 2008 [acesso em 25 abr. 2014]; 12(4):645650. Disponível em: http://www.scielo.br/ scielo.php?script=sci_arttext\&pid=S1414$81452008000400006 \&$ lng $=e n$.

33. Aguiar JM. Violência institucional em maternidades públicas: hostilidade ao invés de acolhimento como uma questão de gênero [tese]. São Paulo: Faculdade de Medicina da Universidade de São Paulo; 2010.
34. Organização Mundial da Saúde. Maternidade segura. Assistência ao parto normal: um guia prático. Genebra (SUI): OMS; 1996.

35. D'oliveira AFPL, Diniz SG, Schraiber LB. Violence against women in health-care institutions: an emerging problem. The Lancet, 2002; 359(11); 1681-5.

36. Brasil. Portal Brasil. Saúde atualiza diretrizes para atenção humanizada a recém-nascido: Bebê deve ter contato pele a pele com mãe logo após nascer e exames de rotina são postergados para depois da primeira hora de vida. $2 \mathrm{Ol} 4$ [acesso em $2 \mathrm{O}$ abr. 2014]. Disponível em: http://www.brasil.gov.br/saude/2O14/O5/ saude-atualiza-diretrizes-para-atencaohumanizada-a-recem-nascido.

37. Foucault M. Microfísica do poder. 23. Ed. Rio de Janeiro: Graal Editora; 1979.

38. Arendt H. On Violence. New York: und London; 1970.

39. Cruz ICF. A Sexualidade, a saúde reprodutiva e a violência contra a mulher negra: aspectos de interesse para assistência de enfermagem. Rev. Esc. Enferm. USP. 2004 [acesso em 30 abr. 2014]; 38(4): 448457. Disponível em: http://www.scielo.br/ scielo.php?script=sci_arttext\&pid=SOO8O62342004000400011\&lng=en.

4O. Griboski RA, Guilhem D. Mulheres e profissionais de saúde: o imaginário cultural na humanização ao parto e nascimento. Texto contexto - enferm. 2006 [acesso em 30 abr. 2014];15(1):107114. Disponível em: http://www.scielo.br/ scielo.php?script=sci_arttext\&pid=SO1O407072006000100013\&lng=en. 